Regular Article

\title{
Genetic deletion of soluble 5'-nucleotidase II reduces body weight gain and insulin resistance induced by a high-fat diet
}

\author{
Manuel Johanns ${ }^{\mathrm{a}, 1}$, Samanta Kviklyte ${ }^{\mathrm{a}, 1}$, Sheng-Ju Chuang ${ }^{\mathrm{a}}$, Katrien Corbeels ${ }^{\mathrm{b}}$, Roxane Jacobs ${ }^{\mathrm{a}}$, \\ Gaëtan Herinckx ${ }^{\mathrm{a}}$, Didier Vertommen ${ }^{\mathrm{a}}$, Olivier Schakman ${ }^{\mathrm{c}}$, Thibaut Duparc ${ }^{\mathrm{d}}$, Patrice D. Cani ${ }^{\mathrm{d}}$, \\ Caroline Bouzin ${ }^{\mathrm{e}}$, Harriet Andersén ${ }^{\mathrm{f}}$, Mohammad Bohlooly- $\mathrm{Y}^{\mathrm{f}}$, Bart Van der Schueren ${ }^{\mathrm{b}}$, \\ Jan Oscarsson ${ }^{\mathrm{f}}$, Mark H. Rider ${ }^{\mathrm{a}, *}$ \\ ${ }^{a}$ Université catholique de Louvain and de Duve Institute, Avenue Hippocrate 75, B-1200 Brussels, Belgium \\ ${ }^{\mathrm{b}}$ Klinische en Experimentele Endocrinologie, Katholieke Universiteit Leuven, Herestraat 49, B-3000 Leuven, Belgium \\ ${ }^{c}$ Université catholique de Louvain and Institute of Neuroscience, Avenue Mounier 53, B-1200 Brussels, Belgium \\ ${ }^{\mathrm{d}}$ Université catholique de Louvain and WELBIO (Waloon Excellence in Life Sciences and Biotechnology), Louvain Drug Research Institute, Avenue Mounier 73, B-1200 \\ Brussels, Belgium \\ e Université catholique de Louvain and Institute of Clinical and Experimental Research, Avenue Hippocrate 55, B-1200 Brussels, Belgium \\ ${ }^{\mathrm{f}}$ Discovery Sciences, IMED Biotech Unit, AstraZeneca, Gothenburg, Sweden
}

\section{A R T I C L E I N F O}

\section{Keywords:}

Soluble 5'-nucleotidase II

CN-II

NT5C2

High-fat diet

Glucose metabolism

Type 2 diabetes

Fat mass

AMPK

\begin{abstract}
A B S T R A C T
We previously investigated whether inhibition of AMP-metabolizing enzymes could enhance AMP-activated protein kinase (AMPK) activation in skeletal muscle for the treatment of type 2 diabetes. Soluble $5^{\prime}$-nucleotidase II (NT5C2) hydrolyzes IMP and its inhibition could potentially lead to a rise in AMP to activate AMPK. In the present study, we investigated effects of NT5C2 deletion in mice fed a normal-chow diet (NCD) or a high-fat diet (HFD). On a NCD, NT5C2 deletion did not result in any striking metabolic phenotype. On a HFD however, NT5C2 knockout (NT5C2 ${ }^{-1-}$ ) mice displayed reduced body/fat weight gain, improved glucose tolerance, reduced plasma insulin, triglyceride and uric acid levels compared with wild-type (WT) mice. There was a tendency towards smaller and fewer adipocytes in epididymal fat from $\mathrm{NT} 5 \mathrm{C} 2^{-/-}$mice compared to WT mice, consistent with a reduction in triglyceride content. Differences in fat mass under HFD could not be explained by changes in mRNA expression profiles of epididymal fat from WT versus NT5C2 $2^{-1-}$ mice. However, rates of lipolysis tended to increase in epididymal fat pads from $\mathrm{NT} 5 \mathrm{C} 2^{-/-}$versus WT mice, which might explain reduced fat mass. In incubated skeletal muscles, insulin-stimulated glucose uptake and associated signalling were enhanced in NT5C2 $2^{-/-}$versus WT mice on HFD, which might contribute towards improved glycemic control. In summary, NT5C2 deletion in mice protects against HFD-induced weight gain, adiposity, insulin resistance and associated hyperglycemia.
\end{abstract}

\section{Introduction}

A high-fat diet (HFD) is linked to the pathogenesis of insulin resistance contributing to the development of type 2 diabetes (T2D). In rats, high-fat feeding was found to induce insulin resistance in liver and skeletal muscle [1]. Adipose tissue in obesity becomes refractory to the anti-lipolytic effect of insulin and the capacity of adipocytes to store triglyceride (TG) is surpassed, resisting fat storage, and lipid accumulates in other tissues [2]. Liver and muscle store the excess energy as fat leading to lipotoxicity, which is thought to be one of the causes of insulin resistance. When blood glucose levels rise after a meal, insulin release stimulates glucose uptake by skeletal muscle and reduces glucose output by the liver, lowering blood glucose to normal concentrations. However, these processes are impaired in insulin resistant individuals eventually leading to permanently elevated blood glucose (T2D) with deleterious effects on health. AMP-activated protein kinase (AMPK) acts as an energy sensor and its activation in skeletal muscle promotes glucose uptake independently of insulin. Also metformin, the most widely prescribed anti-diabetic drug that activates AMPK, acts mainly on the liver to reduce glucose production. However, there is

\footnotetext{
* Corresponding author at: de Duve Institute-UCL, Avenue Hippocrate 75, bte B1.74.02, B-1200 Brussels, Belgium.

E-mail address: mark.rider@uclouvain.be (M.H. Rider).

${ }^{1}$ Equal contributions.
} 
controversy as to whether this effect is AMPK-dependent and indeed whether hepatic AMPK activation inhibits gluconeogenesis [3,4]. Targeting AMPK to promote glucose uptake by muscle to reverse elevated blood glucose has been proposed as a strategy to treat T2D [5].

During prolonged or intense muscle contraction, ATP levels fall leading to a rise in ADP and AMP, the latter being responsible for allosterically stimulating AMPK activity. Increases in AMP and ADP levels activate AMPK by preventing dephosphorylation of AMPKa Thr172 in the activation loop targeted by upstream kinases and a rise in AMP promotes AMPKa Thr172 phosphorylation by the upstream liver kinase B1 (LKB1) [6]. Once activated, AMPK increases ATP production while simultaneously switching off energy consuming pathways, such as lipogenesis, via phosphorylation of its best substrate, acetyl-CoA carboxylase (ACC). The intracellular concentration of free AMP depends on its binding to intracellular proteins and on the activities of enzymes of de novo purine biosynthesis, adenylate kinase, AMP deaminase (AMPD), 5'-nucleotidases (NT5Cs), and the salvage pathway. AMPD1 is highly expressed in skeletal muscle, whereas AMPD2 is predominant in non-muscle tissues such as liver [7]. Cytosolic NT5C1A is specific for AMP and is expressed in muscle and heart, whereas cytosolic NT5C2 preferentially hydrolyzes IMP and is ubiquitous [8]. Because of their catalytic efficiencies $\left(k_{\text {cat }} / K_{\mathrm{M}}\right.$ about $\left.10^{4} \mathrm{M}^{-1} \mathrm{~s}^{-1}\right)$, in spite of having high $K_{\mathrm{M}} \mathrm{s}$ for nucleotides (reaching the mM range), AMPDs and NT5Cs could influence intracellular AMP concentrations [9]. Overexpression of AMP-metabolizing enzymes in HEK293 cells indicated that while AMPD seemed to have little control over intracellular AMP concentrations, NT5C1A exerted a large proportion of control over AMP and its overexpression reduced the oligomycin-induced increases in AMP and ADP along with AMPK activation [9]. Pharmacological AMPD inhibition potentiated AMPK activation by contraction in incubated rat skeletal muscles without increasing glucose uptake, whereas genetic AMPD1 deletion increased AMP levels during contraction of incubated mouse muscles, but AMPK activation was moderate and was only seen in soleus [10]. Gene silencing of NT5C2 in human myotubes and silencing of NT5C1A in mouse muscle led to increases in intracellular AMP:ATP ratio, AMPKa Thr172 phosphorylation and AMPK downstream signalling [11]. The administration of AMPD inhibitors did not improve glucose control in insulin-resistant or diabetic rodent disease models and genetic deletion of AMPD1 in mice did not show any favorable metabolic phenotype on a HFD [12]. It was thus concluded that the development of AMPD inhibitors would not be viable for the treatment of T2D. On the other hand, AMPD2-deficient mice were protected from high fructose diet-induced glycemic dysregulation, mainly due to the inhibition of gluconeogenesis, suggesting that AMPD2 might be a therapeutic target for T2D [13]. Surprisingly, our recent findings indicated that NT5C deletions in mice did not lead to enhanced AMP or ADP concentrations in electrically stimulated skeletal muscles and did not potentiate contraction-induced AMPK activation [13]. However, effects of NT5C deletion in insulin resistance models were not explored. The aim of the present study was to determine whether whole body knockout of NT5C2 could have beneficial effects in mice challenged with a HFD.

\section{Materials and methods}

\subsection{Materials}

Antibodies, synthetic peptides, radiochemicals and all other chemicals and reagents were from sources as previously cited [14] or from Sigma-Aldrich, BE.

\subsection{Generation and management of NT5C2-deficient mice}

Whole body NT5C2-deficient homozygous C57Bl/6 N (NT5C2 ${ }^{-/-}$) mice were originally obtained by breeding C57Bl/6NTac ES cells in mouse strain C57Bl/6NCrl as described previously [14]. The colony was maintained by mixed crossing of heterozygous animals. The Animal Ethics Committee of Université catholique de Louvain approved animal experiments. Mice were housed with a $12 \mathrm{~h}$ light-dark cycle and fed a standard diet until the beginning of the experiment. Cohorts of 9 to 10week-old WT or NT5C2 $2^{-1-}$ littermates were fed either a normal-chow diet (NCD, D12450, Research Diets, USA) or HFD (60\% fat, D12492, Research Diets, USA) for at least 8 consecutive weeks.

\subsection{Measurement of body weight, water intake and indirect calorimetry}

At the start of NCD or HFD feeding, WT and NT5C $2^{-/-}$mice were housed separately with two animals per cage and were weighed on a weekly basis to follow the increase in body weight. Weekly water intake was determined by weight difference. After 8 weeks on a HFD, WT and NT5C $2^{-/-}$mice were allowed to adapt for 7 days to single housing and specific drinking/feeding baskets and animals were individually housed in automated cages for indirect calorimetry (TSE Phenomaster Calocages, Bad Homburg, Germany) in a room at $22^{\circ} \mathrm{C}$ ambient temperature and a $12 \mathrm{~h}$-dark/light cycle with ad libitum access to food and water as described [14]. Food intake, $\mathrm{O}_{2}$ consumption, $\mathrm{CO}_{2}$ production, heat generation and ambulatory activity were recorded over a $72 \mathrm{~h}$ period, but only the last $48 \mathrm{~h}$ were used for calculations to exclude new cage environmental bias.

\subsection{Measurement of fat depot masses}

After 8 weeks of feeding WT and NT5C2 $2^{-/-}$mice on a NCD or HFD, the larger white adipose tissue (WAT) depots indicated in the figures and legends were dissected for measurements of wet weight.

\subsection{RNA extraction and quantitative PCR}

Total mRNA was extracted from epididymal adipose tissue and liver of male WT and NT5C2 $2^{-/-}$mice fed a HFD for 8 weeks using Trizol reagent (Life Technologies, BE) as described [14]. Total RNA (500 ng) was converted to cDNA using M-MLV RT (Life Technologies, BE) with oligo-dT primers following the manufacturer's instructions. Reverse transcription products were diluted 1:3 and $1 \mu \mathrm{l}$ was used for qPCR with Kapa Sybr Fast (Kapa Biosystems/Sigma-Aldrich, BE) with $0.25 \mu \mathrm{M}$ of each primer (Supplementary Table S1; sequences from the Primer Bank collection, Harvard Medical School) in a reaction volume of $10 \mu$ l. The program was initial denaturation at $95^{\circ} \mathrm{C}$ for $3 \mathrm{~min}$, then 40 cycles at $95^{\circ} \mathrm{C}$ for $10 \mathrm{~s}, 62^{\circ} \mathrm{C}$ for $10 \mathrm{~s}, 72^{\circ} \mathrm{C}$ for $30 \mathrm{~s}$ and a final melting curve on a CFX96 Real Time PCR thermocycler (Bio-Rad Laboratories, BE). mRNA expression levels were calculated by the delta $\mathrm{Ct}$ method with the mean of $\beta$-actin, 18S ribosomal RNA, glyceraldehyde-3-phosphate dehydrogenase (GAPDH) and ribosomal protein 19 (RPL19) as references.

\subsection{Oral glucose tolerance test (OGTT) and measurements of plasma insulin, adipokines and metabolites}

After 7 weeks of feeding, at the start of the day/light cycle, food was removed but leaving mice unrestricted access to water. Following $6 \mathrm{~h}$ of starvation, mice were administered glucose by gavage $(2 \mathrm{mg} / \mathrm{g}$ of body weight) and glucose concentrations were measured on blood drops taken from the tip of the tail at intervals over $2 \mathrm{~h}$ using a glucometer (Free Style Lite, Abbott, BE). To measure plasma insulin, blood was taken $30 \mathrm{~min}$ before and $15 \mathrm{~min}$ after glucose administration by massaging the tail and drawing about $50 \mu \mathrm{l}$ of blood into an EDTA-coated capillary tube, from which blood was transferred into $1.5 \mathrm{ml}$ tubes. Following centrifugation $(12,000 \mathrm{~g} \times 5 \mathrm{~min})$, plasma was removed and frozen in liquid $\mathrm{N}_{2}$ for subsequent measurement of insulin levels by ELISA using a commercial kit (Mercodia, SE; cat. no. 10-1249-01).

For adipokine and metabolite measurements, blood was taken either by cardiac puncture or from the vena cava of anesthetized resting mice before tissue dissection, and plasma was prepared as described above. 
Leptin (Crystal Chem \#90030), adiponectin (Crystal Chem \#80569), ghrelin (MyBiosource \#2601787), irisin (MyBiosource \#2600628), GLP1 (MyBiosource \#260820), GIP (MyBiosource \#268941), uric acid (Cayman Chemical \#700320) non-esterified fatty acid (NEFA) (Randox Laboratories \#FA115), cholesterol (Sopachem \#113009910021) and TG (Sopachem \#157109910021) levels were measured [15] with the indicated kits according to the manufacturers' protocols.

\subsection{Measurement of tissue TG content}

Liver, gastrocnemius skeletal muscle and mesenteric adipose tissue were dissected from WT and NT5C2 ${ }^{-1-}$ mice that had been maintained on a HFD for 8-10 weeks. The tissues (about $100 \mathrm{mg}$ wet weight) were homogenized in 10 volumes $(v / w)$ of propan-2-ol/hexane/ $1 \mathrm{M} \mathrm{H}_{2} \mathrm{SO}_{4}$ (14:10:1) in glass tubes. Following the addition of $3 \mathrm{ml}$ of hexane and $7 \mathrm{ml}$ of water, the contents of the tube were mixed thoroughly before centrifugation $(1000 \mathrm{rpm} \times 5 \mathrm{~min}$ ) for phase separation. Two aliquots (0.5-1 ml) of upper hexane layer were removed and dried under vacuum. Buffer ( $0.5 \mathrm{ml}$ of $50 \mathrm{mM}$ Hepes $\mathrm{pH} 7.6,0.1 \%(w / v)$ Triton X-100) was then added for incubation with and without $100 \mathrm{Units} / \mathrm{ml}$ of lipoprotein lipase (from Pseudomonas sp.) for $15 \mathrm{~min}$ at $37^{\circ} \mathrm{C}$. After chilling in ice, aliquots $(0.1-0.3 \mathrm{ml})$ were taken for glycerol assay [16] and, after subtracting blank values for incubations conducted in the absence of lipase, TG content was calculated as mmol of glyceride glycerol/g wet weight of tissue.

\subsection{Measurement of glucose uptake in incubated skeletal muscles}

Extensor digitorum longus (EDL) muscles were dissected from male WT and NT5C2 ${ }^{-/-}$mice maintained either on a NCD or HFD for 8 weeks and incubated with or without electrical stimulation for $20 \mathrm{~min}$ to measure radioactive 2-deoxy-D-glucose uptake as described [14]. Soleus and median gastrocnemius muscles from WT and $\mathrm{NT}_{\mathrm{C}} 2^{-1-}$ mice were also incubated with or without insulin $(100 \mathrm{nM})$ for $30 \mathrm{~min}$ prior to the addition of radioactive 2-deoxyglucose to measure uptake.

2.9. Measurements of lipolysis, AMPK activity, nucleotides, lipogenesis and glucose uptake in incubated white adipose tissue

Epididymal fat pads from male WT and $\mathrm{NT} 5 \mathrm{C} 2^{-/-}$mice fed either a NCD or HFD for 8 weeks were collected in warm $\left(37^{\circ} \mathrm{C}\right)$ Krebs-Ringer Bicarbonate (KRB) buffer. The fat pads were minced with scissors and incubated in $3 \mathrm{ml}$ of KRB buffer containing $4 \%(w / v)$ defatted albumin with or without noradrenalin $(0.5 \mu \mathrm{M})$ for $30 \mathrm{~min}$ at $37^{\circ} \mathrm{C}$ and under an atmosphere of $95 \% \mathrm{O}_{2} / 5 \% \mathrm{CO}_{2}$. After centrifugation $(200 \mathrm{~g} \times 20 \mathrm{~s}$ at $20{ }^{\circ} \mathrm{C}$ ), the underlying media were removed for glycerol assay [16] and the fat pad pieces were frozen in liquid $\mathrm{N}_{2}$. Epididymal fat pad pieces were thawed slightly and homogenized (Ultra-Turrax fitted with a T 10 disperser, $3 \times 10 \mathrm{~s}$ ) in $1 \mathrm{ml}$ of $0.25 \mathrm{M}$ sucrose, $20 \mathrm{mM}$ Hepes, $\mathrm{pH} 7.4$, $1 \mathrm{mM}$ EDTA, $1 \mathrm{mM}$ EGTA, $20 \mathrm{mM} \mathrm{NaF}, 5 \mathrm{mM}$ sodium pyrophosphate, $5 \mathrm{mM} \beta$-glycerol phosphate, $15 \mathrm{mM}$ 2-mercaptoethanol, $0.02 \%(w / v)$ $\mathrm{NaN}_{3}$ with a protease inhibitor cocktail tablet added just prior to homogenization (Roche/Sigma-Aldrich, BE; ref. no. 04693116001). Following centrifugation $\left(16,000 \mathrm{~g} \times 5 \mathrm{~min}\right.$ at $\left.4{ }^{\circ} \mathrm{C}\right)$ the infranatant was removed for immunoprecipitation of $50 \mu \mathrm{l}$ of each extract with antiAMPK $\alpha 1$ antibody [14]. AMPK was assayed in a final volume of $50 \mu 1$ [14] and activity was expressed per unit of LDH, assayed as described [16]. In separate experiments, epididymal fat pads from male WT and NT5C2 ${ }^{-/-}$mice fed on a NCD for 8 weeks were incubated with and without noradrenalin as described above and frozen in liquid $\mathrm{N}_{2}$. The frozen tissues were homogenized using a Dounce homogenizer in $0.5 \mathrm{ml}$ of $0.1 \mathrm{M} \mathrm{HClO}_{4}$ in $40 \% \quad(v / v)$ methanol and centrifuged $5000 \mathrm{~g} \times 10 \mathrm{~min}$, Eppendorf microfuge at $4{ }^{\circ} \mathrm{C}$ ). After removing the

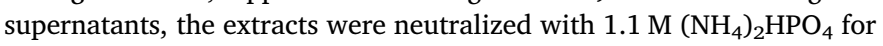
nucleotide measurements by HPLC as described previously [14].

For measurements of lipogenesis, epididymal fat pads from starved male WT and NT5C2 ${ }^{-/-}$mice that had been fed a HFD for 8 weeks were collected in warm KRB buffer and weighed. The fat pads were minced with scissors and incubated in $3 \mathrm{ml}$ of KRB buffer containing $1 \%$ $(w / v)$ defatted albumin and $5 \mathrm{mM}$ glucose. After $10 \mathrm{~min}$, $\left[\mathrm{U}-{ }^{14} \mathrm{C}\right]$ glucose tracer was added $(0.6 \mathrm{mCi} /$ cell incubation) for further incubation with or without insulin $(10 \mathrm{nM})$ for $30 \mathrm{~min}$. Fat pad pieces were harvested by centrifugation in glass tubes $(200 \mathrm{~g} \times 20 \mathrm{~s})$ at $20^{\circ} \mathrm{C}$ and, after removing the underlying medium, $4 \mathrm{ml}$ of $1: 2(v / v) \mathrm{CHCl}_{3}: \mathrm{CH}_{3} \mathrm{OH}$ was added and the tubes were left overnight at $4{ }^{\circ} \mathrm{C}$. After vortexing, the contents of each tube were transferred to a glass Dounce homogenizer for homogenization (20 strokes). The homogenate was transferred to a clean tube and $1.33 \mathrm{ml}$ of $\mathrm{CHCl}_{3}$ followed by $2.4 \mathrm{ml}$ of water was added for phase separation. After vortexing and centrifugation $\left(500 \mathrm{~g} \times 10 \mathrm{~min}\right.$ at $20^{\circ} \mathrm{C}$ ), the upper layer was removed. The lower $\mathrm{CHCl}_{3}$ layer was washed twice with $5 \mathrm{ml}$ of $50 \mathrm{mM} \mathrm{NaCl}$ before an aliquot $(1 \mathrm{ml})$ was counted for radioactivity in $5 \mathrm{ml}$ of Insta-Fluor ${ }^{\mathrm{TM}}$ scintillant (Perkin Elmer, BE) for organic, non-aqueous samples.

Perirenal and inguinal fat from wild-type and $\mathrm{NT5C} 2^{-/-}$mice was incubated with or without insulin $(100 \mathrm{nM})$ prior to the addition of radioactive 2-deoxyglucose for measurements of glucose uptake [14] as described above.

\subsection{Immunoblotting}

Following incubation, gastrocnemius muscles were homogenized in buffer conatinaing $50 \mathrm{mM}$ HEPES, pH 7.5, $1 \mathrm{mM}$ EDTA, $1 \mathrm{mM}$ EGTA, $0.5 \%(v / v)$ 2-mercaptoethanol, $50 \mathrm{mM} \mathrm{NaF}, 5 \mathrm{mM} \mathrm{Na}{ }_{4} \mathrm{P}_{2} \mathrm{O}_{7}, 5 \mathrm{mM}$ sodium $\beta$-glycerophosphate, $1 \mathrm{mM} \mathrm{Na} \mathrm{VO}_{3}, 1 \mathrm{mM}$ dithiothreitol, $1 \%(w /$ v) octylglucoside and Complete protease inhibitor cocktail ${ }^{\mathrm{TM}}$. For fractionation, muscle samples were centrifuged $(100 \mathrm{~g} \times 1 \mathrm{~min})$ to eliminate debris and then at $20000 \mathrm{~g} \times 10 \mathrm{~min}$ to seperate a crude membrane pellet from the cytosolic fraction. The pellet was then solubilized in Laemmli SDS-PAGE sample buffer. Cytosolic protein concentrations were measured and $\sim 30 \mu \mathrm{g}$ (or up to $20 \mu \mathrm{l}$ of membrane fraction corrected for corresponding cytosolic protein concentrations) were loaded on $4-15 \%(w / v)$ polyacrylamide gradient gels (Biorad) for SDS-PAGE and immunoblotting. Antibodies were diluted as follows in Tris-buffered saline (TBS) containing $0.1 \%(v / v)$ Tween and 5\% $(w / v)$ BSA: anti-total glucose transporter (GLUT4) (Cell Signalling \#2213) 1:1000, anti-phospho Thr642 AKT substrate of $160 \mathrm{kDa}$ (AS160) (Cell Signalling \#8881) 1:1000, anti-total AS160 (Cell Signalling \#2670) 1:1000, antiphospho Ser473 protein kinase B (PKB) (Cell Signalling \#4058) 1:1000, anti-total pan PKB (Cell Signalling \#9272) 1:5000, anti-total GAPDH (Millipore \#MAB374) 1:20.000, anti-phospho Ser79 ACC (Millipore \#07-303) and anti-total ACC (Cell Signalling \#3662) 1:1000.

\subsection{Adipocyte number and cell size distribution}

After 8 weeks on a NCD or HFD, epididymal adipose tissue was dissected from WT and NT5C2 $2^{-1-}$ mice and fixed in $4 \%(v / v)$ formaldehyde for embedding in paraffin. Sections $(5 \mu \mathrm{m})$ were stained with hematoxylin and eosin using a standard protocol. Images were then digitalized using a SCN400 slide scanner (Leica Biosystems, DE) at x20 magnification. Adipocyte size was determined using the image analysis tool Author, version 2017.1; 6.9.2 (Visiopharm, DK). Mean adipocyte size and number was calculated from five regions of interest (ROIs) per adipose tissue section.

\subsection{Statistical analysis}

The results are expressed as means with error bars representing standard errors of the mean (S.E.M.). Statistical analysis was performed by one-way ANOVA, otherwise an unpaired Student's two-sided $t$-test was used as indicated. 


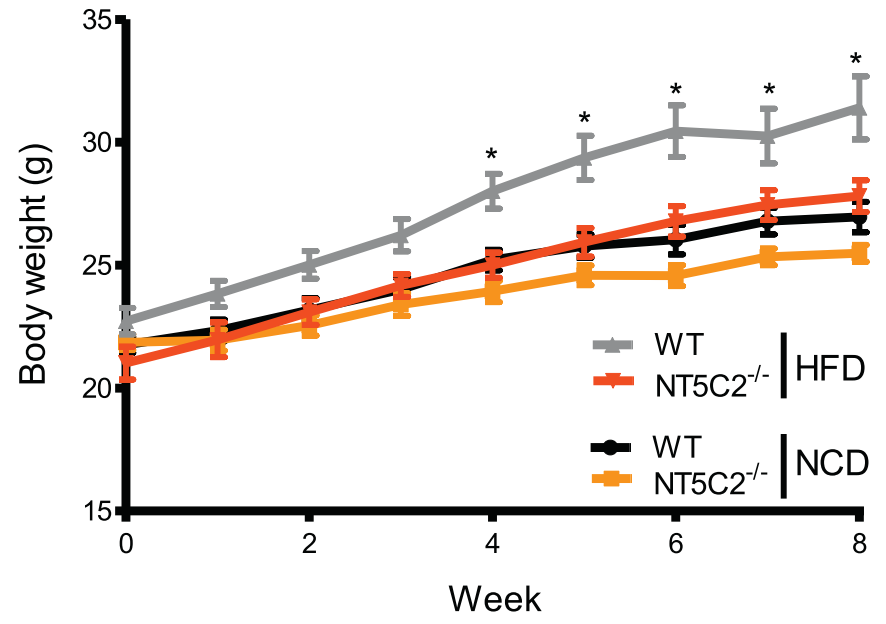

Fig. 1. Body weight gain of WT and NT5C $2^{-/-}$mice on a NCD versus HFD. The results are means \pm S.E.M. for 12 individual WT or NT5C $2^{-/-}$mice on a NCD or HFD. "Indicates a significant difference for WT versus $\mathrm{NT} 5 \mathrm{C} 22^{-/-}$mice on a HFD by one-way ANOVA $(P<0.05)$.

\section{Results}

3.1. Food intake, indirect calorimetry, body and adipose tissue depot masses and tissue TG content in WT and NT5C2 $2^{-1-}$ mice on a HFD versus NCD

WT and NT5C $2^{-1-}$ mice were fed a NCD or HFD for 8 weeks. On a NCD, there was no significant difference in body weight between WT and $\mathrm{NT} 5 \mathrm{C} 2^{-/-}$mice over the feeding period (Fig. 1). As expected, WT mice on a HFD showed significantly increased body weight gain compared to their WT littermates on a NCD. NT5C2 $2^{-/-}$mice also increased their body weight on a HFD, but as of 4 weeks their body weight was significantly less compared with WT mice on a HFD (Fig. 1). The differences in body mass were not due to changes in food consumption (Supplementary Fig. S1A) or water intake (not shown), which were not significantly different between WT and $\mathrm{NT}_{5} \mathrm{C}^{-/-}$mice on either a NCD or HFD and locomotor behavior in mice fed a NCD or HFD was unaffected by NT5C2 deletion (Supplementary Fig. S1B). However, although not significant, there was a tendency towards increased $\mathrm{O}_{2}$ consumption (Supplementary Fig. S1C), respiratory exchange ratio (RER) (Supplementary Fig. S1D) and heat production (Supplementary Fig. S1E) for NT5C2 ${ }^{-1-}$ compared to WT mice on a HFD. The RER values below 0.70 (Supplementary Fig. S1D) are likely due to the extreme high fat content of the diet and the closed respiratory system which may underestimate tissue gas exchange by increasing $\mathrm{CO}_{2}$ content in the environment. To see whether total body weight differences could be attributed to differences in fat mass, we dissected the largest fat depots for weighing. Epididymal, subcutaneous and inguinal WAT masses increased significantly by 2 - to 3-fold comparing WT mice on a HFD versus NCD (Fig. 2A,C,D). Interestingly, epididymal, subcutaneous, mesenteric and inguinal WAT masses were significantly reduced in NT5C2 $2^{-1-}$ versus WT mice on a HFD, and the fat masses of depots from the NT5C2-deficient mice were about the same as those of WT mice on a NCD (Fig. 2A-D). No increase in brown adipose tissue (BAT) fat mass from WT mice on a HFD was seen compared with BAT from WT mice on a NCD and there was no significant difference in BAT fat mass from $\mathrm{NT} 5 \mathrm{C} 2^{-1-}$ mice versus WT mice on a HFD (data not shown). Liver, gastrocnemius muscle and mesenteric WAT from WT and NT5C2 ${ }^{-/-}$mice on a HFD were dissected and extracted for measurements of TG content expressed per tissue wet weight. TG content was unchanged in gastrocnemius but decreased slightly in liver from NT5C2 ${ }^{-/-}$versus WT mice (Fig. 2E). Also, TG content decreased significantly $(\sim 60 \%)$ in mesenteric WAT from NT5C2 $2^{-/-}$versus WT mice (Fig. 2E).

\subsection{OGTT, plasma insulin and metabolite concentrations in WT and NT5C2 ${ }^{-/-}$mice on a HFD versus NCD}

WT and NT5C2 $2^{-1-}$ mice on a NCD or on a HFD were starved and subjected to an OGTT. No differences in blood glucose levels after starvation were seen in WT and NT5C2 $2^{-1-}$ mice on a NCD or HFD and, over $120 \mathrm{~min}$, blood glucose concentrations were the same in WT and NT5C $2^{-/-}$mice fed a NCD (Fig. 3A). As expected, blood glucose levels were elevated in WT mice on a HFD, but $\mathrm{NT} 5 \mathrm{C} 2^{-1-}$ mice on a HFD displayed significantly reduced blood glucose concentrations at 60, 90 and $120 \mathrm{~min}$ (Fig. 3A). Quantification of "area under the curve" (AUC) for blood glucose levels indicated significant increases in both WT and NT5C $2^{-/-}$mice due to a HFD, but on a HFD NT5C2 deletion significantly reduced the AUC compared to WT mice (Fig. 3B).

In WT mice on a HFD compared with a NCD, plasma insulin levels were increased by $\sim 70 \%$ in the starved state (Fig. 3C), indicative of insulin resistance. Following glucose injection, WT mice displayed increased insulin levels on a HFD compared with NCD (Fig. 3C). On the other hand, $\mathrm{NT} 5 \mathrm{C} 2^{-/-}$mice displayed significantly reduced plasma insulin levels on a HFD both in the starved condition and in response to glucose administration compared with WT mice (Fig. 3C).

Blood was taken from resting mice to measure the plasma concentrations of some metabolites. High levels of circulating TG, cholesterol and NEFAs are known risk factors for the development of insulin resistance. TG concentrations were the same in plasma from WT and $\mathrm{NT} 5 \mathrm{C} 2^{-/-}$mice on a NCD, but were significantly decreased by $\sim 50 \%$ in plasma from $\mathrm{NT}_{5} \mathrm{C}^{-/-}$versus WT mice on a HFD (Fig. 4A). Cholesterol levels increased slightly and NEFA concentrations increased roughly 3-fold in plasma from WT mice on a HFD versus NCD, but for NT5C $2^{-1-}$ mice the increase on a HFD was not significant (Fig. 4B,C). Plasma concentrations of the adipokines adiponectin (Fig. 4D) and leptin (Fig. 4E) involved in improved glucose homeostasis and satiety, respectively, were slightly lower in NT5C2 ${ }^{-/-}$compared to wild-type mice on a HFD, probably due to reduced body fat mass. Plasma concentrations of the myokine irisin (Fig. 4F) involved in WAT browning, the gastrokine ghrelin (Fig. 4G) regulating appetite and the incretins GLP-1 and GIP (Fig. 4H,I) involved in regulation of insulin secretion were all unchanged in $\mathrm{NT5C} 2^{-/-}$compared to wild-type mice on a HFD. By contrast, plasma concentrations of uric acid (Fig. 4J), a product of purine degradation (Supplementary Fig. S2L) and contributory factor for the development of insulin resistance [17,18] were significantly decreased by $\sim 20 \%$ in NT5C2 $2^{-/-}$mice on a HFD.

\subsection{Contraction- and insulin induced glucose uptake in incubated EDL muscles from WT and NT5C2 $2^{-1-}$ mice on a HFD versus NCD}

No differences in basal or contraction-induced ( $\sim 2$-fold) glucose uptake were observed in incubated EDL muscles from WT versus NT5C2 ${ }^{-/-}$mice maintained on a HFD or NCD (Fig. 5A). Also EDL muscle masses from WT and NT5C2 $2^{-1-}$ mice maintained on a NCD or HFD were similar (Fig. 5B). Incubation of soleus muscles from WT mice on a HFD with insulin did not significantly increase glucose uptake, whereas in soleus from NT5C2 deficient mice glucose uptake was increased $>2$-fold by insulin (Fig. 5C). This was in agreement with more pronounced increases in insulin-induced PKB and AS160 phosphorylation as well as GLUT4 translocation in gastrocnemius muscles from NT5C2 ${ }^{-1-}$ compared with WT mice seen in parallel incubations (Fig. 5D,E). By contrast, incubation of perirenal and inguinal fat pads either from WT or NT5C2 $2^{-/-}$mice on a HFD with insulin did not result in increased glucose uptake (not shown).

3.4. Measurements of lipolysis and AMPKa1 activity in epididymal fat pads from WT and NT5C2 $2^{-/-}$mice on a HFD versus NCD incubated with and without noradrenalin

Epididymal fat pads from WT and $\mathrm{NT} 5 \mathrm{C} 2^{-/-}$mice maintained on a 
A

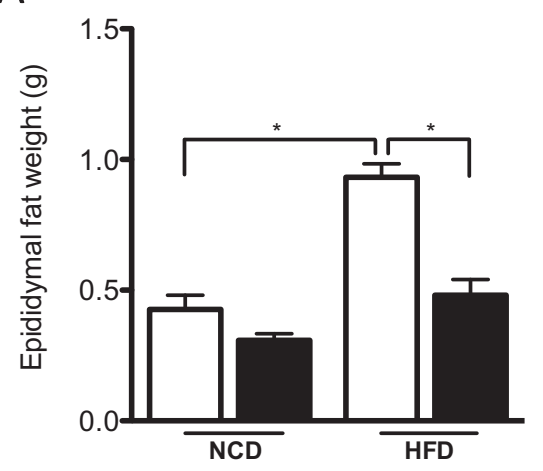

C

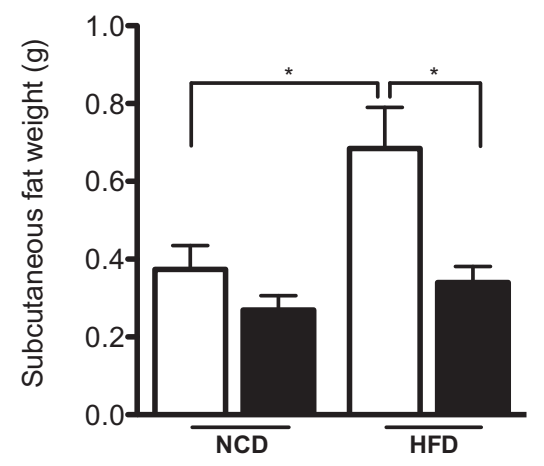

B

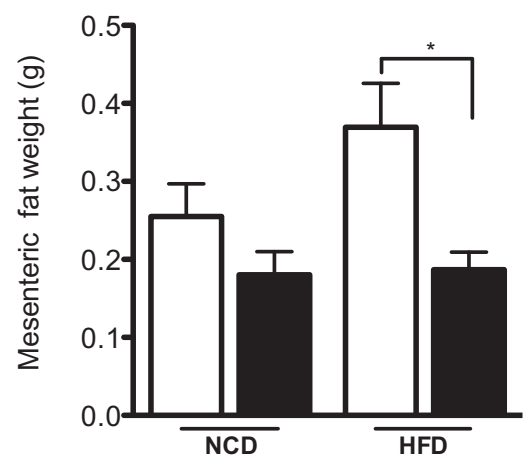

Fig. 2. Adipose tissue masses from WT and NT5C $2^{-/-}$mice on a NCD versus HFD together with TG content of liver, skeletal muscle and WAT from from WT versus NT5C $2^{-/-}$mice on a HFD. WAT masses of fat depots from WT (open bars) versus NT5C $2^{-/-}$mice (black bars) on a NCD and HFD are shown (A-D). The results are means \pm S.E.M. for 7 individual WT or 7 individual NT5C $2^{-/-}$mice on a NCD or HFD. *Indicates a significant difference by one-way ANOVA $(P<0.05)$. In $(\mathrm{E})$ mesenteric WAT, liver and gastrocnemius skeletal muscle were dissected for measurements of TG content and the results are means \pm S.E.M. for 6 individual WT or 6 individual NT5C2 ${ }^{-/-}$mice on a HFD. "Indicates a significant difference by an unpaired $t$-test $(P<0.05)$.

D
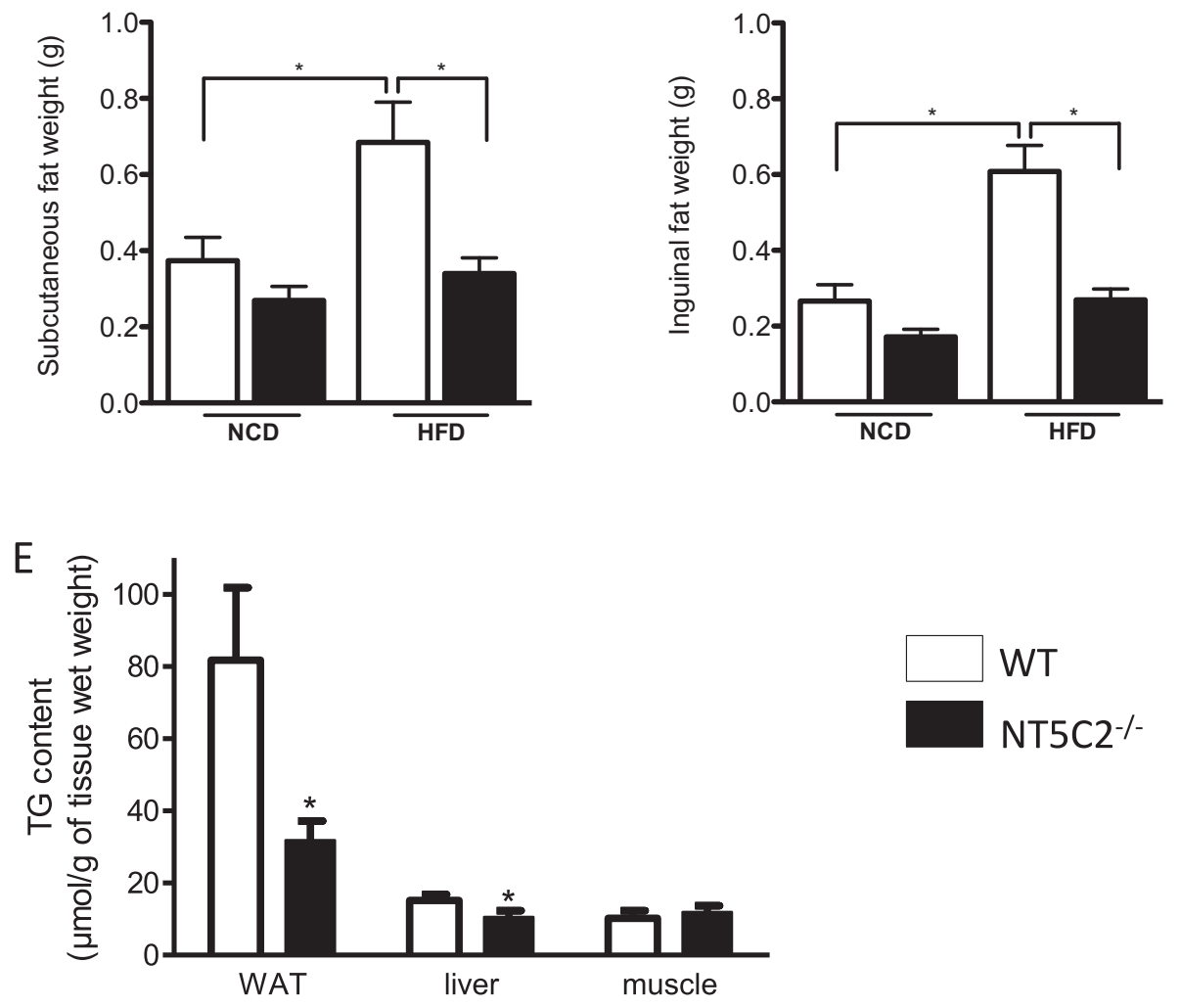

NCD or HFD were incubated with and without noradrenalin for measurements of medium glycerol concentrations (as an index of lipolysis) and tissue AMPKa1 activity. Basal rates of lipolysis were similar in incubated epididymal fat pads from WT and NT5C2 $2^{-/-}$mice on a NCD or HFD (Fig. 6A). Incubation with noradrenalin increased the rate of lipolysis $\sim 3$-fold in epididymal fat pads from WT and NT5C $2^{-/-}$mice on a NCD. However, noradrenalin-stimulated lipolysis was blunted to a similar extent in epididymal fat pads from both WT and NT5C2 $2^{-/-}$ mice on a HFD compared with a NCD (Fig. 6A). There was a tendency towards increased basal and noradrenalin-stimulated rates of lipolysis in incubated fat pads from NT5C2 $2^{-/-}$versus WT mice on a HFD, which in the long-term might partly explain the reduction in fat mass (Fig. 2AD). AMPK activation decreases $\beta$-agonist-stimulated lipolysis and rodent adipocytes mainly express catalytic AMPK $\alpha 1$ subunits [19]. On the other hand, AMPK activation has been reported to increase basal lipolysis [20]. Epididymal fat pad extracts were therefore immunoprecipitated to measure AMPK $\alpha 1$ activity. As expected, incubation with noradrenalin increased AMPK activity $\sim 2$-fold in fat pads from both WT and NT5C2 $2^{-/-}$mice on a NCD, but AMPK activity in incubated fat pads from WT and NT5C $2^{-/-}$mice on a HFD compared with a NCD was not decreased significantly (Fig. 6B). On the other hand, although not significant, there was a tendency towards increased AMPK activity in incubated fat pads from NT5C $2^{-/-}$compared with WT mice on a NCD or HFD in both the basal and noradrenalin-stimulated conditions, reflected by a significant increase in basal and noradrenalin-induced ACC Ser79 phosphorylation due to NC5C2 deletion on a HFD (Fig. 6C). Accordingly, in epididymal fat from WT and NT5C2 ${ }^{-\prime}$ - mice on a NCD, an increase in AMP concentration was only seen in fat pads from $\mathrm{NT5C} 2^{-/-}$mice in response to noradrenalin treatment compared with the basal condition (Supplementary Fig. S2C). There was, however, a potentiation of the increase in IMP levels in fat pads from $\mathrm{NT} 5 \mathrm{C} 2^{-1-}$ mice in response to noradrenalin treatment compared with the basal condition (Supplementary Fig. S2D) consistent with enzyme deletion. In fat pads from both WT and $\mathrm{NT}_{5} \mathrm{C} 2^{-{ }^{-}}$mice incubated with noradrenalin, there was a decrease in inosine levels compared with the basal condition (Supplementary Fig. S2F). 
A

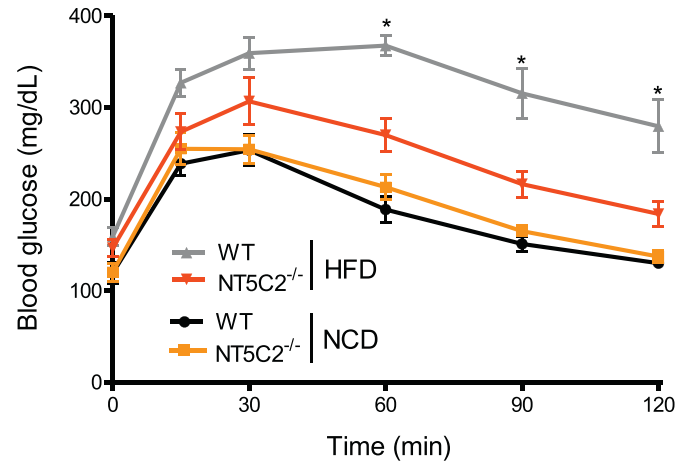

$\mathrm{B}$

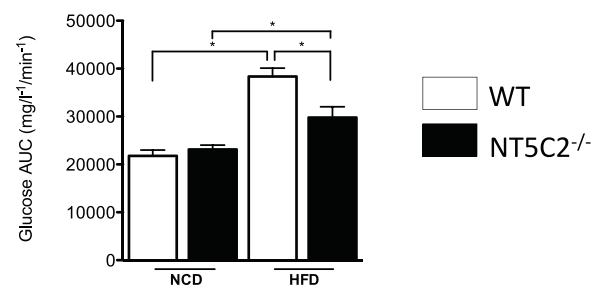

C

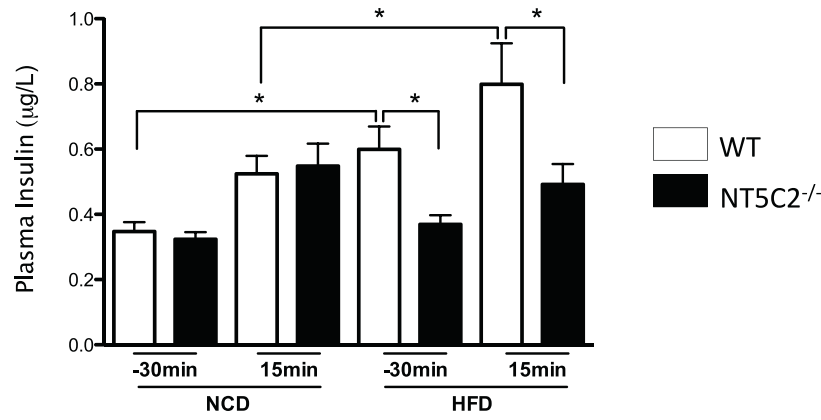

Fig. 3. OGTT and plasma insulin concentrations for WT and $\mathrm{NT}^{2} \mathrm{C}^{-{ }^{-/}}$mice on a NCD versus HFD. For the OGTT (A), *indicates a significant difference for WT versus NT5C2 knockout mice on a HFD by one-way ANOVA $(P<0.05)$. The results are means \pm S.E.M. for 11 individual WT and 11 individual $\mathrm{NT} \mathrm{C} 2^{-/-}$mice. In the histograms (B,C), glucose AUC and plasma insulin values for 8 individual WT (open bars) versus 9 individual $\mathrm{NT}_{\mathrm{C}} 2^{-/-}$mice (black bars) on a NCD or HFD are shown and the results are means \pm S.E.M. "Indicates a significant difference by one-way ANOVA $(P<0.05)$.

\subsection{Measurement of lipogenesis in epididymal fat pads from WT and NT5C2 $2^{-1-}$ mice on a NCD incubated with and without insulin}

No significant differences in basal or insulin-stimulated rates of lipogenesis were observed between incubated epididymal fat pads from WT and NT5C2 $2^{-/-}$mice maintained on a NCD (rates as nmol [U- $\left.{ }^{14} \mathrm{C}\right]$ glucose incorporation into total lipids $/ 30 \mathrm{~min} / \mathrm{g}$ wet weight $n=4$, WT control: $68 \pm 22$; WT insulin: $134 \pm 51$; $\mathrm{NT}^{2} 2^{-/-}$control: $95 \pm 53$; NT5C2 $2^{-/-}$insulin: $180 \pm 62$ ).

\subsection{Adipocyte number and cell size distribution in epididymal fat pads from WT and NT5C2 ${ }^{-1-}$ mice on a HFD}

Analysis of hematoxylin and eosin-stained white epididymal adipose tissue from WT and NT5C2 $2^{-/-}$mice on a HFD revealed a slight drop in total and large adipocyte number in tissues from $\mathrm{NT} 5 \mathrm{C} 2^{-/-}$ mice but no change in average surface area (Supplementary Fig. S3). The average number and surface area of small adipocytes were not significantly different. However, field-restricted analysis of histological sections only reflects cell density whereas the overall number of adipocytes increases with fat pad mass in WT C57BL/6 mice on a HFD [21].
3.7. Changes in gene expression in epididymal WAT and liver from WT and NT5C $2^{-/-}$mice on a HFD

Total mRNA was extracted from epididymal WAT and liver of male WT and NT5C2 $2^{-1-}$ mice fed on a HFD for quantitative PCR analysis. The expression of genes encoding proteins involved in lipolysis, lipogenesis and fatty acid transport along with transcription factors including several implicated in WAT "browning", hormones and tissue inflammation markers mostly did not change in epididymal WAT from NT5C $2^{-1-}$ versus WT mice (Fig. 7A). There were however, significant decreases in the expression of the transcription factor sterol-responsive element binding protein 2 (SREBP2) involved in cholesterol homeostasis, the "beige" adipocyte marker transmembrane protein 26 (TMEM26) and the inflammatory infiltration marker integrin alpha $\mathrm{X}$ (ITGAX)/CD11c in epididymal WAT from NT5C $2^{-/-}$versus WT mice, and there was a 2 -fold increase in the expression of adiponectin and a 3.5-fold increase in expression of the BAT-specific transcription factor "zinc finger in the cerebellum 1" (Zic1) that were almost significant. No changes in expression of the enzymes phosphoenolpyruvate carboxykinase (PEPCK)1, PEPCK2 and glucose-6-phosphatase (G6Pase), GLUT2 or the transcription factor forkhead box protein O1 (FOXO1) in livers from $\mathrm{NT}_{5} \mathrm{C}^{-/-}$versus WT mice on a HFD were observed (Fig. 7B) that could explain improved glucose tolerance by decreasing hepatic gluconeogenesis in $\mathrm{NT} 5 \mathrm{C} 2^{-/-}$mice.

\section{Discussion}

In the present study, we show that NT5C2 deletion improved glucose tolerance and decreased plasma insulin levels in mice on a HFD (Fig. 3), an animal model of diet-induced T2D. No differences in muscle mass and basal or contraction-induced rates of glucose uptake were observed in incubated EDL muscles from WT or NT5C2 $2^{-1-}$ mice regardless of diet (Fig. 5A,B). However, the insulin-induced rate of glucose uptake in incubated soleus along with PKB Ser473 phosphorylation and GLUT4 translocation in incubated gastrocnemius muscles from NT5C $2^{-1-}$ versus WT mice on a HFD were increased (Fig. 5C-F), whereas for incubated perirenal and inguinal fat pads either from WT or $\mathrm{NT5C} 2^{-/-}$mice on a HFD, insulin did not increase glucose uptake, presumably due to complete insulin resistance on a HFD. We believe that NT5C2 deletion would enhance glucose uptake by insulin in skeletal muscle in mice on a HFD via increased phosphatidylinositol 3kinase signalling, as evidenced by increased PKB Ser473 phosphorylation, rather than via AMPK, since basal AMPK activity was unaffected in incubated skeletal muscles from $\mathrm{NT5C} 2^{-/-}$mice [14] and glucose uptake was unaffected by contraction in incubated EDL muscles from WT versus NT5C2 $2^{-1-}$ mice maintained on a HFD or NCD (Fig. 5A). Improved glucose clearance on a HFD as a result of NT5C2 deletion would thus mainly be due to increased skeletal muscle glucose uptake in vivo. Indeed, the fact that blood glucose levels after starvation were unaffected by NT5C2 deletion (time zero in Fig. 3A) and hepatic glucose production maintains blood glucose during starvation suggests that improved glucose tolerance was due to increased responsiveness of skeletal muscle to insulin. This might have been due to lower levels of circulating uric acid in NT5C2 $2^{-1-}$ mice on a HFD (Fig. 4J), probably due to lack of NT5C2 and decreased purine degradation as a consequence (Supplementary Fig. S2L). High plasma uric acid has been directly linked to the onset of insulin resistance $[17,18]$ and it is known that a HFD induces hyperuricaemia [22].

NT5C $2^{-/-}$mice on a HFD displayed a reduction in body weight gain (Fig. 1) and decreased mass of several major body WAT deposits (Fig. 2) compared with WT mice on a HFD. The difference in body weight between WT mice and NT5C2 $2^{-/-}$mice after 8 weeks on a HFD was $\sim 3 \mathrm{~g}$ (Fig. 1), while the cumulated reduction in WAT fat mass in $\mathrm{NT} 5 \mathrm{C} 2^{-1-}$ mice versus WT mice on a HFD was $\sim 1.5 \mathrm{~g}$ (Fig. 2). Given that all of the body white fat was not taken by dissection, reduced body weight in NT5C $2^{-/-}$mice on a HFD might well be accounted for by 
A

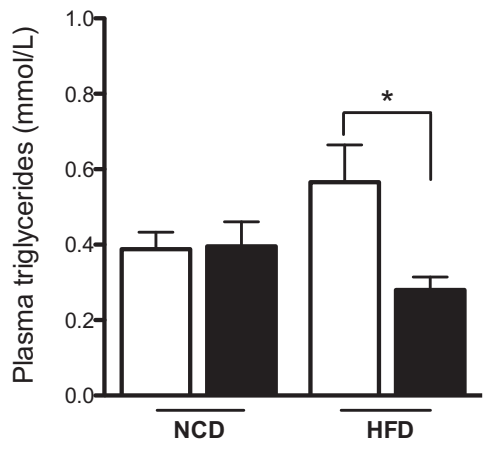

B

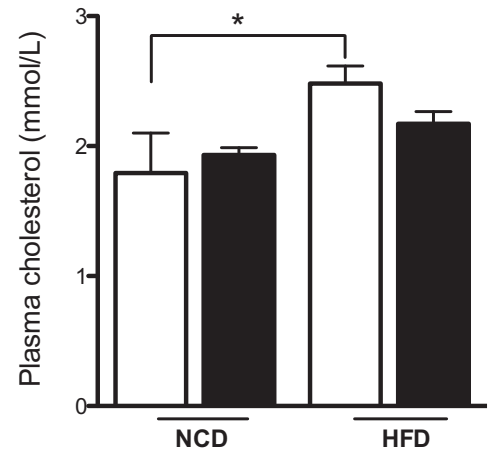

C

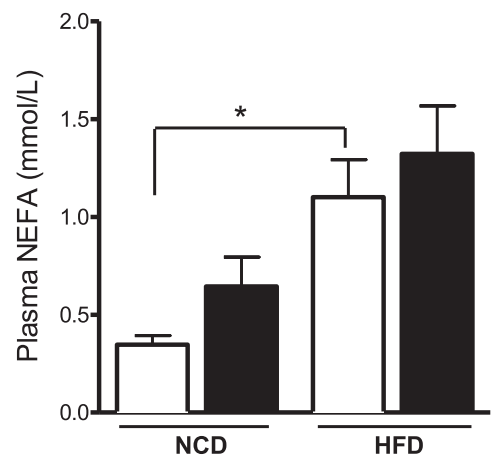

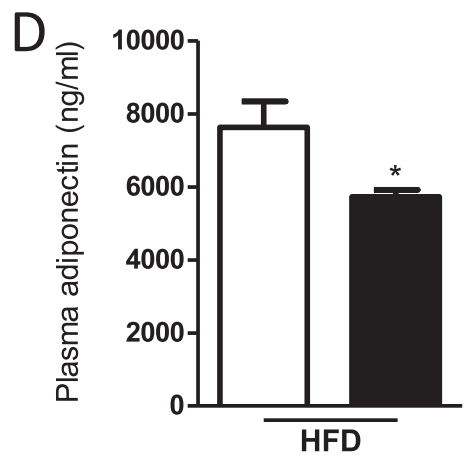
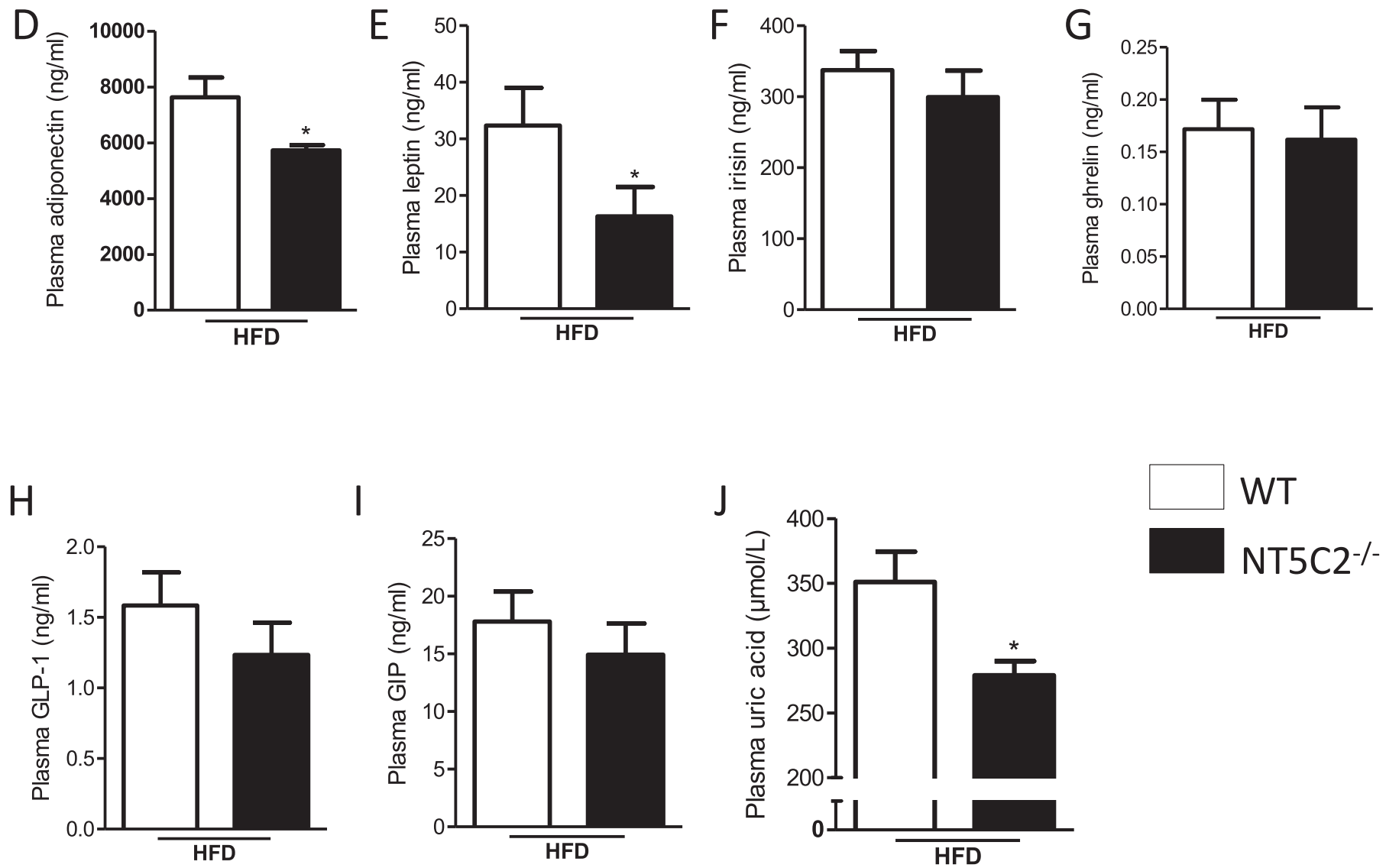

Fig. 4. Metabolite and cytokine concentrations in plasma from WT versus NT5C2 $2^{-/}$mice on a NCD versus HFD. In the histograms, plasma concentrations for WT (open bars) versus NT5C $2^{-\prime-}$ mice (black bars) on on a NCD or HFD are shown. The results are means \pm S.E.M. for 9 individual (A,B,C) WT or 6 individual NT5C2 ${ }^{-\prime}$ - mice on a NCD or HFD. *Indicates a significant difference by one-way ANOVA (A-C) or an unpaired $t$-test (D-J) $(P<0.05)$.

decreased mass of WAT depots. A tendency towards increased basal and noradrenalin-stimulated lipolysis was seen in NT5C2 $2^{-/-}$versus WT mice (Fig. 6A). Consistently, there was a trend towards higher plasma NEFA levels in NT5C2 ${ }^{-/}$versus WT mice (Fig. 4C) and, on a wet weight basis, mesenteric adipose tissue TG content was significantly decreased in NT5C2 $2^{-1-}$ versus WT mice on a HFD (Fig. 2E). Histological analysis of epididymal adipose tissue from WT and NT5C2 $2^{-/-}$ mice on a HFD revealed only slight differences in adipocyte size or density. Thus, NT5C2 deletion resulted in weight loss of fat depots and decreased TG content without affecting adipocyte size/density, possibly as a result of reduced adipocyte hyperplasia that normally occurs in mice on a HFD [21].

Silencing of NT5C2 in human myotubes was shown to increase the intracellular AMP:ATP ratio, to increase AMPKa Thr172 phosphorylation and to increase AMPK downstream signalling [11]. However, we found that whole body NT5C2 deletion in mice did not lead to enhanced AMP or ADP concentrations in contracting muscles and no potentiation of AMPK activation by electrical stimulation was observed [14], consistent with the lack of effect of NT5C2 deletion on contraction-stimulated glucose uptake (Fig. 5 A). In incubated epididymal fat pads from mice on a NCD or a HFD, AMPK activity tended to be higher in both the basal and noradrenalin-stimulated conditions as a result of NT5C2 deletion (Fig. 6B) and on a NCD incubation with noradrenalin increased AMP levels in fat pads from NT5C2 $2^{-/-}$mice (Fig. S2C), although the nucleotide data were gathered on a very low sample size. Also, on a HFD, fat pad ACC phosphorylation was significantly 
A

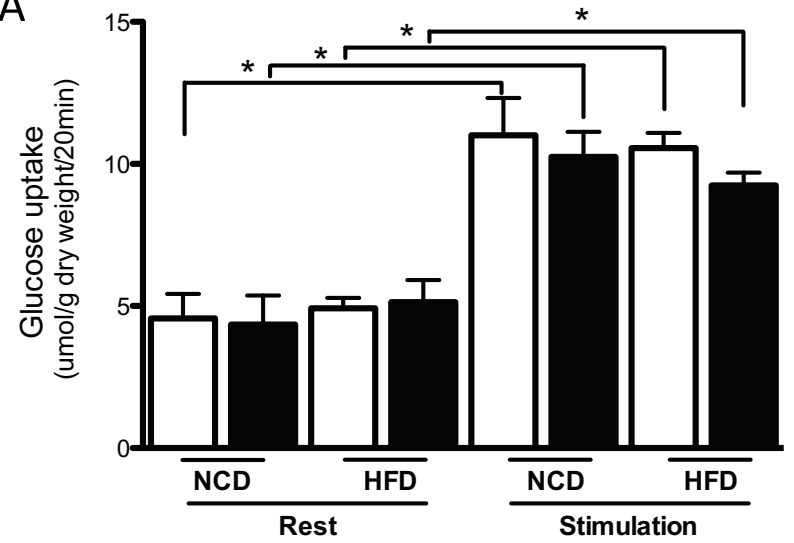

B

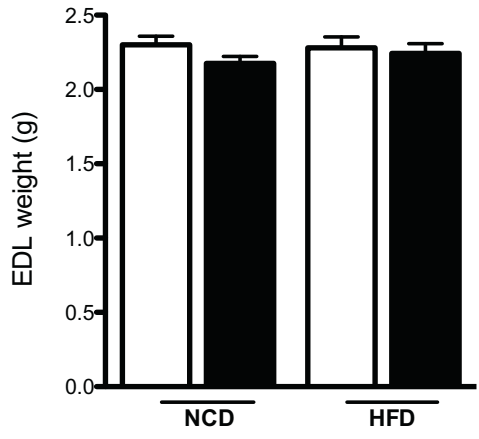

C

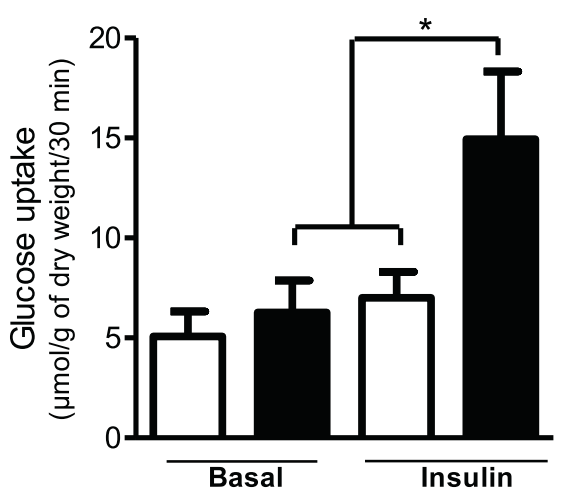

E

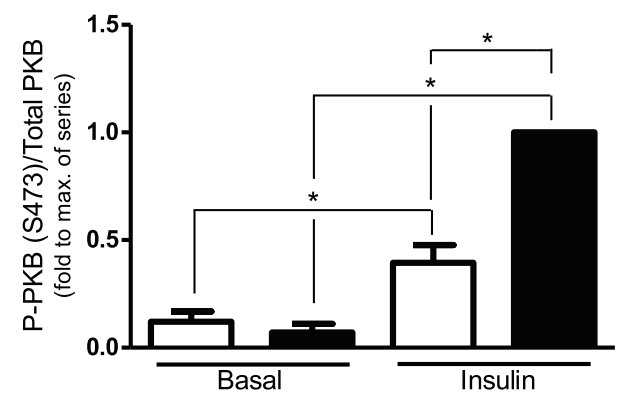

D

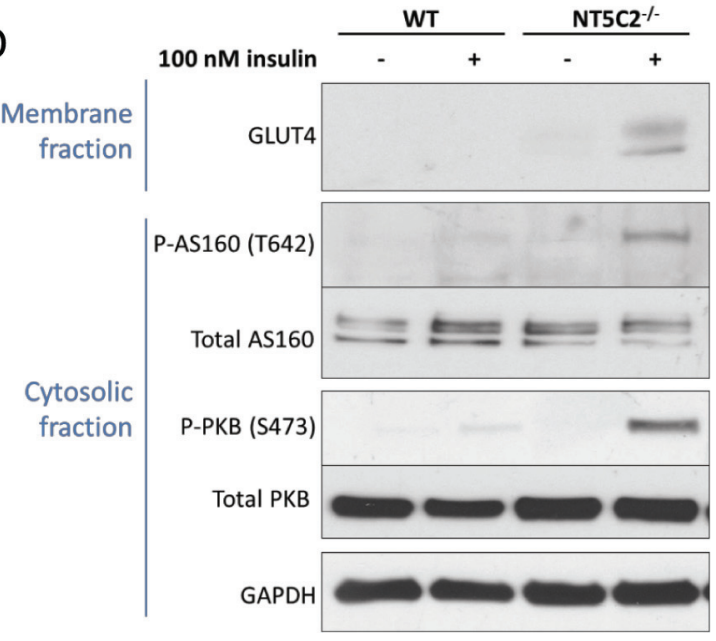

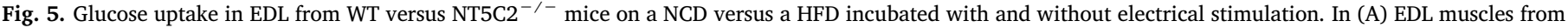

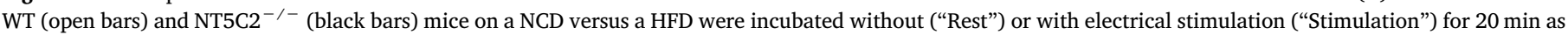

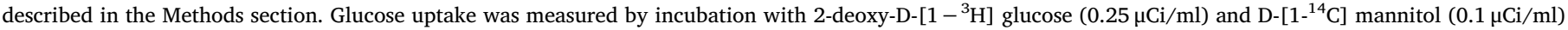

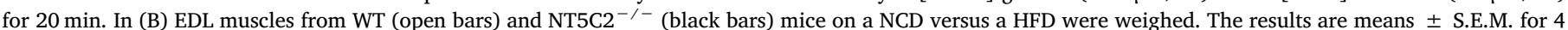

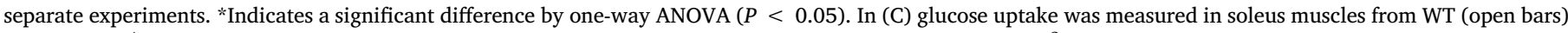

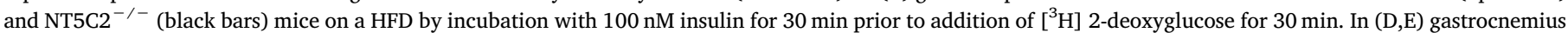

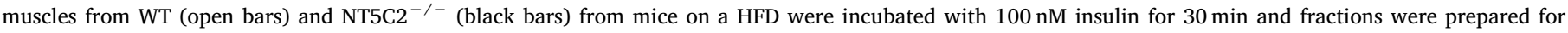

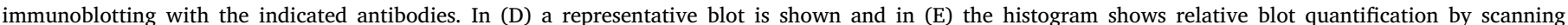
densitometry. The results are means \pm S.E.M. for 6 separate experiments. *Indicates a significant difference by one-way ANOVA $(P<0.05)$.

increased in the basal and noradrenalin-stimulated conditions in incubated fat pads from NT5C2 $2^{-/-}$versus WT mice (Fig. 6C). However, subtle long-term changes in metabolites due to NT5C2 deletion that could lead to AMPK activation would probably relax and be lost in ex vivo incubations of skeletal muscles and epididymal fat pads. The demonstration of AMPK activation and any slight changes in AMP in vivo is very difficult because the interruption of blood flow during dissection leads to AMPK activation due to hypoxia-induced changes in adenine nucleotides. In livers from NT5C2 ${ }^{-/-}$compared with livers from WT mice on a HFD there was only a very slight decrease in TG content
(Fig. 2E), which might be an indication that AMPK activity was not increased in the liver as a result of NT5C2 deletion, since in mice on a HFD administered metformin or 5-aminoimidazole-4-carboxamide ribonucleotide, which activate hepatic AMPK in vivo, there was a marked reduced liver TG content expressed per gram wet weight of tissue $[23,24]$. Consistently, in primary hepatocytes from NCD-fed WT versus NT5C2 ${ }^{-/-}$mice, measurements of adenine nucleotides and AMPK activity in basal and phenformin-treated conditions were not significantly different (data not shown).

AMPK activation has been shown to be involved in the "browning" 
A

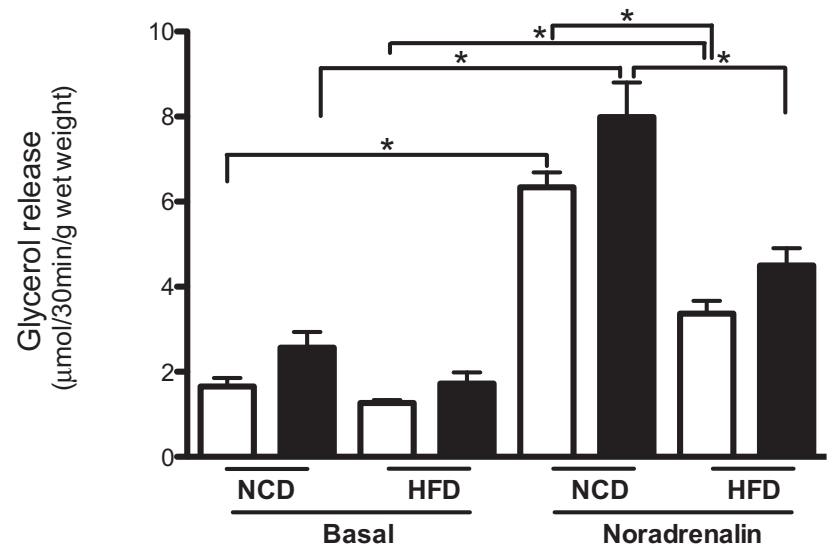

B

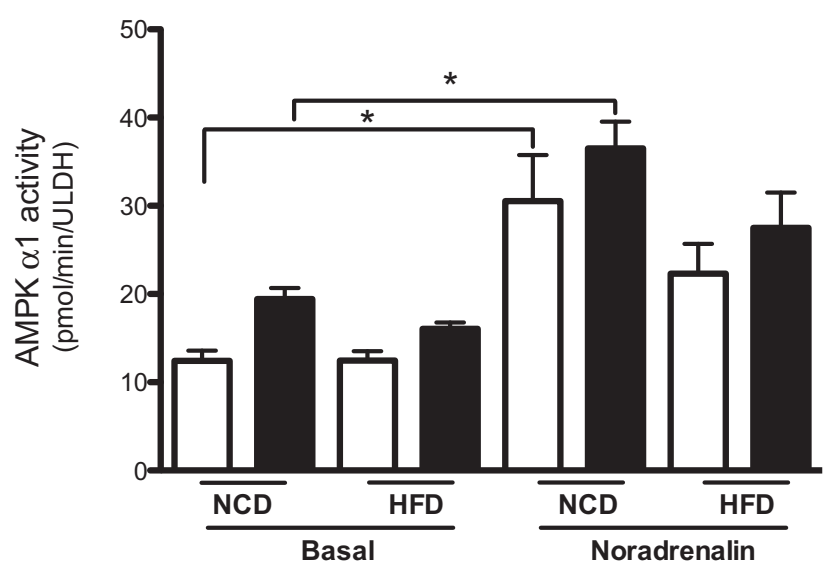

C
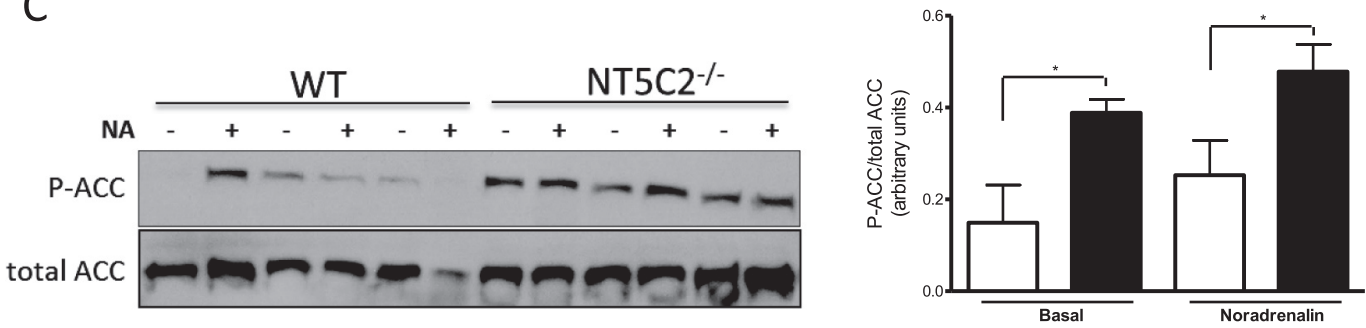

Fig. 6. Rates of lipolysis and AMPK activity in epididymal fat pads from WT versus NT5C2 ${ }^{-1-}$ mice on a NCD versus a HFD incubated with or without noradrenalin. Epididymal fat pads from WT (open bars) and NT5C2 $2^{-1-}$ (black bars) mice on a NCD versus a HFD were incubated with or without noradrenalin for 30 min as described in the Methods section. In (A) medium glycerol concentrations were measured and in (B) extracts were immunoprecipitated with anti-AMPKa1 antibody prior to AMPK assay. The results are means \pm S.E.M. for 4-6 separate experiments. *Indicates a significant difference by one-way ANOVA $(P<0.05)$. In $(C)$ extracts of fat pads from 3 WT versus 4 NT5C2 ${ }^{-1-}$ mice on a HFD were immunoblotted with anti-phospho Ser79 ACC versus anti-total ACC antibodies (left hand panel) and the histogram shows relative blot quantification by scanning densitometry (right hand panel). The results are means \pm S.E.M. *Indicates a significant difference $(P<0.05$, unpaired $t$-test).

of WAT into "beige" or "brite" adipose tissue, a hybrid of BAT and WAT, which could increase energy expenditure to reduce body weight [25]. We could not see histological evidence of browning in epididymal WAT, however mRNA analysis indicated a trend towards increased Zic1 expression in NT5C2 ${ }^{-1-}$ versus WT mice on a HFD and Zic1 seems to be involved in BAT development [26]. Although not significant, metabolic cage experiments revealed a trend towards increased $\mathrm{O}_{2}$ consumption, RER and heat production in NT5C2 $2^{-1-}$ versus WT mice on a HFD. However, because energy expenditure and $\mathrm{O}_{2}$ consumption were normalized to body weight, this might have been due to the leaner phenotype of the NT5C2 $2^{-/-}$versus WT mice. It could be that in $\mathrm{NT5C} 2^{-/-}$ mice, WAT depots other than epididymal fat become beige or that uncoupling occurs in another tissue such as muscle or liver.

In conclusion, the beneficial effects of NT5C2 deletion on glucose homeostasis, body weight gain and WAT fat mass in mice on a HFD were probably due to increased responsiveness of skeletal muscle to insulin and possibly also increased energy expenditure, perhaps due to long-term changes in hormone secretion from endocrine organs, and we cannot exclude AMPK activation in WAT playing a role. None of the plasma cytokine/hormone levels that we measured (Fig. 4D-I) would explain the observed beneficial effects of NT5C2 deletion and lower circulating levels of adiponectin and leptin in NT5C2 $2^{-1-}$ mice on a HFD (Fig. 4D,E) would not be consistent with loss of weight and improved insulin sensitivity. In fact adiponectin mRNA tended to increase 
A

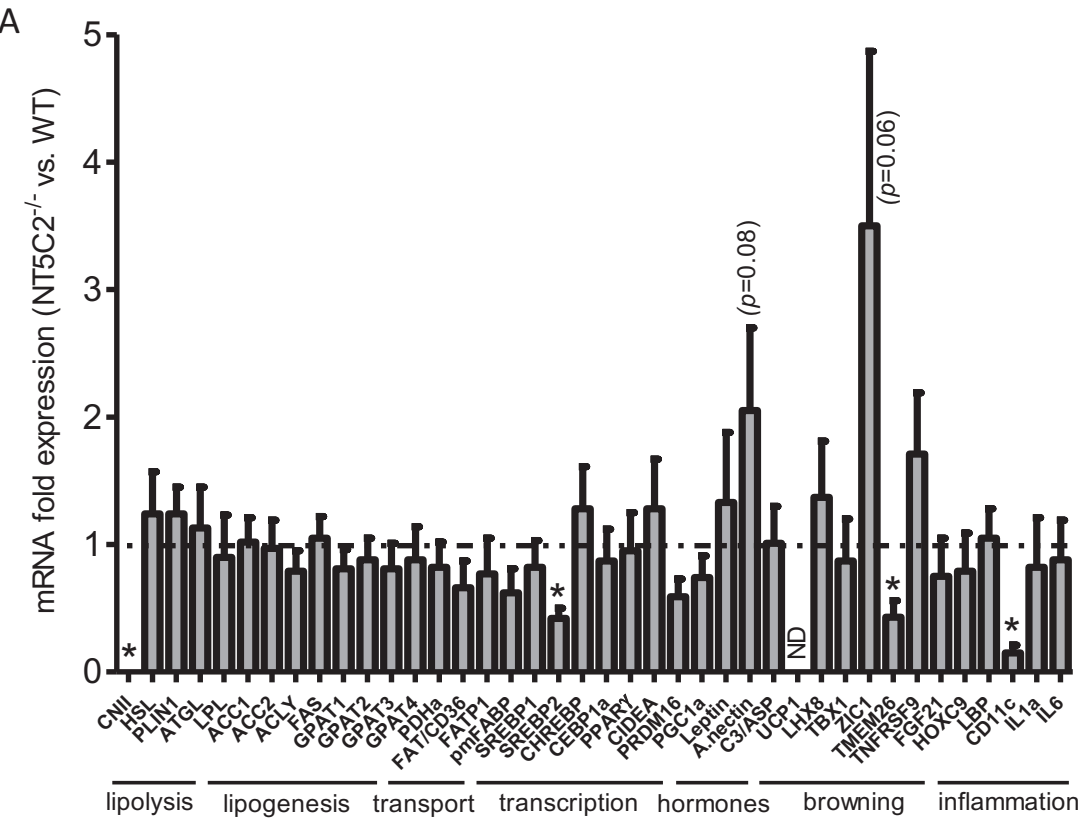

B

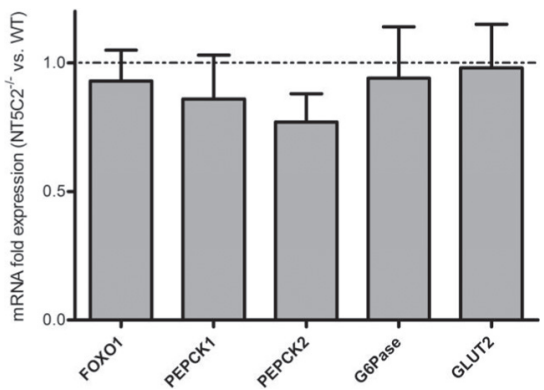

Fig. 7. mRNA expression analysis of epididymal adipose tissue (A) and liver (B) of WT versus NT5C2 $2^{-/}$mice on a HFD. In the histograms, values of relative mRNA expression are shown for epididymal WAT (A) and liver (B). The results are means \pm S.E.M. from 5 individual (WT) or 6 individual NT5C2 ${ }^{-/}$animals. *Indicates a significant difference $(P<0.05$, unpaired $t$-test). ND - not detectable.

(Fig. 7A) and the pronounced reduction in adipose tissue mass could mean that more adiponectin and leptin would be produced per gram/ cell of adipose tissue in $\mathrm{NT5C} 2^{-/-}$mice. An intriguing possibility is that due to NT5C2 deletion, a reduction in inosine or a rise in IMP could somehow affect adipose tissue development or be involved in hypothalamic/systemic hormone secretion to affect insulin sensitivity and perhaps also energy homeostasis. Taken together, our results suggest that NT5C2 might be a viable drug target for the treatment of T2D, as deletion of the enzyme protects against HFD-induced (adipose) weight gain as well as insulin resistance and associated hyperglycaemia. Interestingly, pharmacological NT5C2 inhibitors have been developed recently as anti-cancer agents [27] and it would be worth investigating whether such compounds have anti-diabetic potential.

\section{Acknowledgements}

We thank Louis Hue for his advice and interest and Hubert Plovier for help with the OGTT. S.K. was supported by the Interuniversity Poles of Attraction Belgian Science Policy (P7/13), M.J. was supported by the Fund for Research Training in Industry and Agriculture (F.R.I.A., Belgium) and S.-J.C. was supported by a doctoral grant from the French Community of Belgium. D.V. was "Logisticien de Recherche Principal" (UCL). P.D.C is senior research associate at the FRS-FNRS (Fonds de la Recherche Scientifique), and recipient of FRFS-WELBIO grant WELBIOCR-2017-C02 (continuation grant 2017), Funds Baillet Latour (Grant for Medical Research 2015) and ERC Starting Grant 2013 (Starting grant 336452-ENIGMO). The work was funded by the Interuniversity Poles of Attraction Belgian Science Policy (P7/13), and by the Fonds de la Recherche Scientifique (FNRS, Belgium) under Grant number T.0008.15.

\section{Disclosures}

The authors do not have any conflict of interest, financial or otherwise, to declare.

\section{Author contributions}

J.O. and M.H.R. initiated the project. NT5C2 knockout mice were generated by H.A. under the supervision of M.B-Y. S.K. and M.H.R. were involved in conception and design of experiments. R.J. and G.H. were involved in animal maintenance, crossings, genotyping and dissection. O.S., K.C. and B.V. performed phenotype testing. S.K. and M.J. carried out most of the experimental work with help from R.J. and S.J.C. C.B. performed histological analyses and D.V. carried out nucleotide measurements. P.D.C. and T.D. provided help and advice on adipose tissue dissection, plasma metabolite and glucose measurements. S.K. analyzed the data for interpretation along with M.H.R. M.H.R., S.K. and M.J. drafted the article with final approval by M.B-Y. 


\section{Appendix A. Supplementary data}

Supplementary data to this article can be found online at https:// doi.org/10.1016/j.ymgme.2019.01.017.

\section{References}

[1] N.D. Oakes, G.J. Cooney, S. Camilleri, D.J. Chisholm, E.W. Kraegen, Mechanisms of liver and muscle insulin resistance induced by chronic high-fat feeding, Diabetes 46 (1997) 1768-1774.

[2] K.N. Frayn, Adipose tissue and the insulin resistance syndrome, Proc. Nutr. Soc. 60 (2001) 375-380.

[3] C.M. Hasenour, D.E. Ridley, F.D. James, C.C. Hughey, E.P. Donahue, B. Viollet, M. Foretz, J.D. Young, D.H. Wasserman, Liver AMP-activated protein kinase is unnecessary for gluconeogenesis but protects energy state during nutrient deprivation, PLoS One 12 (2017) e0170382.

[4] G. Rena, D.G. Hardie, E.R. Pearson, The mechanisms of action of metformin, Diabetologia 60 (2017) 1577-1585.

[5] D.G. Hardie, Targeting an energy sensor to treat diabetes, Science 357 (2017) 455-456.

[6] D.G. Hardie, AMPK-sensing energy while talking to other signaling pathways, Cell Metab. 20 (2014) 939-952.

[7] T. Morisaki, R.L. Sabina, E.W. Holmes, Adenylate deaminase. A multigene family in humans and rats, J. Biol. Chem. 265 (1990) 11482-11486.

[8] V. Bianchi, J. Spychala, Mammalian 5'-nucleotidases, J. Biol. Chem. 278 (2003) $46195-46198$.

[9] C. Plaideau, J. Liu, J. Hartleib-Geschwindner, L. Bastin-Coyette, F. Bontemps, J. Oscarsson, L. Hue, M.H. Rider, Overexpression of AMP-metabolizing enzymes controls adenine nucleotide levels and AMPK activation in HEK293T cells, FASEB J. 26 (2012) 2685-2694.

[10] C. Plaideau, Y.C. Lai, S. Kviklyte, N. Zanou, L. Loforen, H. Andersen, D. Vertommen, P. Gailly, L. Hue, et al., Effects of pharmacological AMP deaminase inhibition and Ampd1 deletion on nucleotide levels and AMPK activation in contracting skeletal muscle, Chem. Biol. 21 (2014) 1497-1510.

[11] S.S. Kulkarni, H.K. Karlsson, F. Szekeres, A.V. Chibalin, A. Krook, J.R. Zierath, Suppression of 5'-nucleotidase enzymes promotes AMP-activated protein kinase (AMPK) phosphorylation and metabolism in human and mouse skeletal muscle, J. Biol. Chem. 286 (2011) 34567-34574.

[12] T. Admyre, L. Amrot-Fors, M. Andersson, M. Bauer, M. Bjursell, T. Drmota, S. Hallen, J. Hartleib-Geschwindner, B. Lindmark, et al., Inhibition of AMP deaminase activity does not improve glucose control in rodent models of insulin resistance or diabetes, Chem. Biol. 21 (2014) 1486-1496.

[13] A.W. Hudoyo, T. Hirase, A. Tandelillin, M. Honda, M. Shirai, J. Cheng, H. Morisaki,
T. Morisaki, Role of AMPD2 in impaired glucose tolerance induced by high fructose diet, Mol. Genet. Metab. Rep. 13 (2017) 23-29.

[14] S. Kviklyte, D. Vertommen, X. Yerna, H. Andersen, X. Xu, P. Gailly, Y.M. Bohlooly, J. Oscarsson, M.H. Rider, Effects of genetic deletion of soluble 5'-nucleotidases NT5C1A and NT5C2 on AMPK activation and nucleotide levels in contracting mouse skeletal muscles, Am. J. Physiol. Endocrinol. Metab. 313 (2017) E48-e62.

[15] L. Geurts, A. Everard, M. Van Hul, A. Essaghir, T. Duparc, S. Matamoros, H. Plovier, J. Castel, R.G. Denis, et al., Adipose tissue NAPE-PLD controls fat mass development by altering the browning process and gut microbiota, Nat. Commun. 6 (2015) 6495

[16] M.H. Rider, L. Hue, Regulation of fructose 2,6-bisphosphate concentration in white adipose tissue, Biochem. J. 225 (1985) 421-428.

[17] A. Causevic, S. Semiz, A. Macic Dzankovic, B. Cico, T. Dujic, M. Malenica, T. Bego, Relevance of uric acid in progression of type 2 diabetes mellitus, Bosn. J. Basic Med. Sci. 10 (2010) 54-59.

[18] Y. Zhu, Y. Hu, T. Huang, Y. Zhang, Z. Li, C. Luo, Y. Luo, H. Yuan, I. Hisatome, et al., High uric acid directly inhibits insulin signalling and induces insulin resistance, Biochem. Biophys. Res. Commun. 447 (2014) 707-714.

[19] M. Daval, F. Diot-Dupuy, R. Bazin, I. Hainault, B. Viollet, S. Vaulont, E. Hajduch, P. Ferre, F. Foufelle, Anti-lipolytic action of AMP-activated protein kinase in rodent adipocytes, J. Biol. Chem. 280 (2005) 25250-25257.

[20] S.J. Kim, T. Tang, M. Abbott, J.A. Viscarra, Y. Wang, H.S. Sul, AMPK phosphorylates Desnutrin/ATGL and hormone-sensitive lipase to regulate lipolysis and fatty acid oxidation within adipose tissue, Mol. Cell. Biol. 36 (2016) 1961-1976.

[21] J. Jo, O. Gavrilova, S. Pack, W. Jou, S. Mullen, A.E. Sumner, S.W. Cushman, V. Periwal, Hypertrophy and/or hyperplasia: dynamics of adipose tissue growth, PLoS Comput. Biol. 5 (2009) e1000324.

[22] M.A. Ogryzlo, Hyperuricemia induced by high fat diets and starvation, Arthritis Rheum. 8 (1965) 799-822.

[23] Y. Kita, T. Takamura, H. Misu, T. Ota, S. Kurita, Y. Takeshita, M. Uno, N. Matsuzawa-Nagata, K. Kato, et al., Metformin prevents and reverses inflammation in a non-diabetic mouse model of nonalcoholic steatohepatitis, PLoS One 7 (2012) e43056.

[24] B.S. Henriksen, M.E. Curtis, N. Fillmore, B.R. Cardon, D.M. Thomson, C.R. Hancock, The effects of chronic AMPK activation on hepatic triglyceride accumulation and glycerol 3-phosphate acyltransferase activity with high fat feeding, Diabetol. Metab. Syndr. 5 (2013) 29.

[25] E.A. Day, R.J. Ford, G.R. Steinberg, AMPK as a therapeutic target for treating metabolic diseases, Trends Endocrinol. Metab. 28 (2017) 545-560.

[26] E. Mueller, Browning and graying: novel transcriptional regulators of Brown and Beige fat tissues and aging, Front. Endocrinol. (Lausanne) 7 (2016) 19.

[27] Z. Marton, R. Guillon, I. Krimm, R. Preeti, D. Rahimova, L.P. Egron, N. Jordheim, C. Dumontet Aghajari, et al., Identification of noncompetitive inhibitors of cytosolic 5'-nucleotidase II using a fragment-based approach, J. Med. Chem. 58 (2015) 9680-9696. 